\title{
Intraductal Non-Comedo Breast Adenocarcinoma
}

National Cancer Institute

\section{Source}

National Cancer Institute. Intraductal Non-Comedo Breast Adenocarcinoma. NCI

Thesaurus. Code C5137.

A ductal carcinoma in situ of the breast characterized by the presence of sheets of tumor cells without evidence of central necrosis or cell death. 